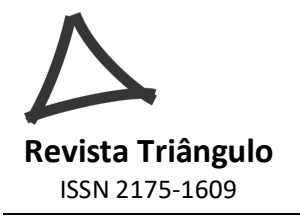

\title{
ENSINO DE FILOSOFIA EM CAMPINAS SP: PERCEPÇÕES DE DOCENTES E DISCENTES E DESCOMPASSO ENTRE A ÉTICA ARISTOTÉLICA E O AGIR NO AMBIENTE ESCOLAR
}

\author{
PHILOSOPHY TEACHING IN CAMPINAS SP: PERCEPTIONS OF TEACHERS AND \\ STUDENTS AND MISMATCH BETWEEN ARISTOTELIAN ETHICS AND ACTION IN THE \\ SCHOOL
ENSEÑANZA DE FILOSOFÍA EN CAMPINAS SP: PERCEPCIONES DE DOCENTES Y DISCENTES Y DESCOMPASO ENTRE LA ÉTICA ARISTOTÉLICA Y EL AGIR EN EL MEDIO AMBIENTE ESCOLAR

\author{
Agnaldo Ronie Pezarini \\ E-mail: rpezarini@gmail.com \\ Samuel Mendonça \\ E-mail: samuelms@gmail.com \\ Pontifícia Universidade Católica de Campinas \\ Agências de fomento: CAPES e CNPq.
}

\begin{abstract}
RESUMO
Este artigo tem como objeto de investigação o ensino de filosofia no município de Campinas, Estado de São Paulo. A singularidade deste manuscrito diz respeito à pesquisa empírica, realizada com estudantes e professores. $\mathrm{O}$ problema do artigo consistiu na pergunta: qual é a percepção de docentes e discentes de filosofia, da Diretoria de ensino Campinas Leste, acerca da ética aristotélica? Quanto aos procedimentos metodológicos foi utilizada a pesquisa bibliográfica, documental e empírica. Quanto aos resultados obtidos, afirma-se que o ensino de filosofia nas unidades escolares em questão é visto como salutar no processo de formação dos cidadãos e a ética aristotélica faz parte da proposta curricular e é vivenciada pelos estudantes, no entanto e paradoxalmente, observaram-se ações contraditórias entre estudantes no que diz respeito a virtudes aristotélicas investigadas, a amizade, a justiça e a liberdade, demonstrando descompasso entre o pensamento aristotélico e a vivência no ambiente escolar.
\end{abstract}

PALAVRAS CHAVE: Ensino de filosofia. Ética aristotélica. Formação ética.

\begin{abstract}
This article has as object of investigation the teaching of philosophy in the city of Campinas, State of São Paulo. The singularity of this manuscript concerns empirical research, carried out with students and teachers. The problem of the article was the question: what is the perception of teachers and students of the Board of Education Campinas East about Aristotelian ethics? As for the methodological procedures, the bibliographic and documental review was used in addition to the empirical research. As for the results obtained, it is stated that the teaching of philosophy in the school units in question is seen as salutary in the process of training citizens and Aristotelian ethics is part of the curricular proposal and is experienced by the students, however and paradoxically, There are contradictory actions among students regarding investigated Aristotelian virtues, friendship, justice and freedom, demonstrating a mismatch between Aristotelian thought and living in the school environment.
\end{abstract}

KEYWORDS: Philosophy Teaching. Aristotelian Ethics. Virtues. Ethical training. 


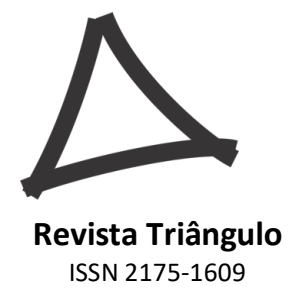

\section{RESUMEN}

Este artículo tiene como objeto de investigación la enseñanza de filosofia en el municipio de Campinas, Estado de São Paulo. La singularidad de este manuscrito se refiere a la investigación empírica, realizada con estudiantes y profesores. El problema del artículo consiste en la pregunta: ¿cuál es la percepción de docentes y discentes del Directorio de enseñanza Campinas Este acerca de la ética aristotélica? En cuanto a los procedimientos metodológicos se utilizó la revisión bibliográfica además de la investigación empírica. En cuanto a los resultados obtenidos, se afirma que la enseñanza de filosofia en las unidades escolares en cuestión es visto como saludable en el proceso de formación de los ciudadanos y la ética aristotélica forma parte de la propuesta curricular y es vivenciada por los estudiantes, sin embargo y paradójicamente, se trata de acciones contradictorias entre estudiantes en lo que se refiere a las virtudes aristotélicas investigadas, la amistad, la justicia y la libertad, demostrando descompás entre el pensamiento aristotélico y la vivencia en el ambiente escolar.

PALABRAS-CLAVE: Enseñanza de filosofia. Ética aristotélica. Formación ética.

\section{INTRODUÇÃO}

O ensino de filosofia tem sido tematizado de formas distintas na literatura, com ênfase na questão do método de ensino (GALLO, 2006, 2012), a forma de se pensar a filosofia de forma filosófica, isto é, como experimento ou por meio do filosofar (KOHAN, 2004), ensino que toma por a base a necessidade da autoeduação ou educação aristocrática (MENDONÇA, 2012, 2018) ou mesmo como hipótese de ruptura e linhas de fuga (GALLO; ASPIS, 2010), entre outras matrizes e vertentes (FÁVERO, et. alli., 2004; TESSER et. alli., 2012). Colocar em relevo o ensino de filosofia, justamente no contexto de aprovação de legislação que remete a filosofia do currículo do ensino médio brasileiro para a Base Nacional Comum Curricular, como é o caso da Lei 13.415/2017 (BRASIL, 2017), é relevante porque não se tem o desenho preciso de como a fílosofia permanecerá no currículo do Ensino Médio a partir do ano de 2018. Assim, na perspectiva da legislação que se reconfigura, pensou-se a necessidade de se compreender o sentido da filosofia junto a professores e estudantes do ensino médio, no município de Campinas, SP.

Esta investigação diz respeito a recorte da pesquisa de dissertação de mestrado, desenvolvida no Programa de Pós-Graduação em Educação da PUC Campinas, que contou com financiamento da CAPES e do CNPq. Em linhas gerais, neste trabalho buscou-se compreender se o ensino de filosofia, das escolas estaduais da Diretoria Campinas Leste, SP, está pautado na ética de Aristóteles. Um estudo cuidadoso sobre o pensamento de Aristóteles, 


\section{Revista Triângulo}

ISSN 2175-1609

tematizado no campo educacional foi feito por Cenci (2012), da mesma forma que outro estudo sobre a excelência moral para se pensar a formação de professores foi realizada por Safa e Mendonça (2012). Há, portanto, muitos exemplos que evidenciam o sentido e importância de Aristóteles para a educação. A razão da escolha do filósofo grego tem relação direta com a necessidade de discussões que envolvem a ética na escola e Aristóteles é referência do Currículo de Filosofia do Estado de São Paulo. Quanto aos procedimentos metodológicos foi utilizada a pesquisa bibliográfica e documental, além da pesquisa empírica. A pesquisa empírica teve como instrumentos de coleta de dados o uso de questionário fechado aplicado pela ferramenta survio, entrevista e grupo focal.

Quanto aos resultados obtidos, é possível argumentar que o ensino de filosofia nas unidades escolares em questão é visto como salutar no processo de formação dos cidadãos e a ética aristotélica faz parte da proposta curricular e é vivenciada pelos estudantes, no entanto e paradoxalmente, observaram-se ações contraditórias entre estudantes no que diz respeito a virtudes aristotélicas investigadas, a amizade, a justiça e a liberdade, demonstrando descompasso entre o pensamento aristotélico e a vivência no ambiente escolar. Os resultados indicam que, além de conhecer o pensamento de um filósofo, neste caso, Aristóteles, na Educação Básica, é preciso praticar preceitos virtuosos para que o ensino de filosofia seja consequente neste nível de ensino.

Este artigo está organizado, do ponto de vista formal, em dois momentos. Apresentase, brevemente, a trajetória do ensino de filosofia e aspectos teóricos sobre virtudes aristotélicas, seguindo da exposição do método, algumas informações da amostra e discussão dos resultados.

\section{TRAJETÓRIA DO ENSINO DE FILOSOFIA E VIRTUDES ARISTOTÉLICAS}

De acordo com Mazai (2001, p. 3), a apresentação de breve trajetória sobre o ensino de filosofia remete à necessidade de retomada de ações de religiosos da Companhia de Jesus, dado que foram eles os responsáveis pela educação em nosso país à época, mesmo que a filosofia estivesse voltada para a elite intelectual e social. De forma mais precisa e amparada às Políticas Públicas, o ensino de filosofia passa a ter força com a Lei de Diretrizes e Bases. A primeira Lei de Diretrizes e Bases da Educação Nacional é promulgada em 1961, sob o número 4024. A 


\section{Revista Triângulo}

ISSN 2175-1609

filosofia é inserida no currículo de forma complementar, deixando a obrigatoriedade que lhe era conferida anteriormente. Ainda em sua cronologia inconstante pode-se verificar que a filosofia teve em sua trajetória, um constante vai e vem, no que se refere à sua obrigatoriedade nos currículos. No entanto, no ano de 2008 foi sancionada a Lei $\mathrm{n}^{\circ} 11.684 / 2008$, que alterou a Lei $\mathrm{n}^{\mathrm{o}} 9394 / 1996$, e tornou obrigatório o ensino de filosofia para todas as escolas do ensino médio. A especificidade desta Lei, de 2008, determinou a obrigatoriedade dessa disciplina nas três séries do ensino médio. Diante do quadro apontado sobre a obrigatoriedade do ensino desse componente curricular, poder-se-ia considerar a utilização dela como instrumento de controle. Sá Júnior (2010, p. 2) discute esta questão, dialogando com Silvio Gallo, ao afirmar que: “[...] o ensino de filosofia pode ser usado também como um instrumento de controle. Afinal, qual o interesse do Estado para fazer cidadãos pensantes, críticos, reflexivos?”

Então, a desconfiança de se estabelecer a filosofia no currículo do ensino médio para as três séries já se constitui um problema filosófico. Afinal, estaria o Estado interessado, mesmo, na formação crítica dos jovens? Embora a resposta a esta pergunta possa parecer óbvia, no sentido de que o poder público deseja a formação de pessoas com competência crítica para se pensar e repensar o mundo, é possível argumentar que as condições garantidas para a presença da filosofia nas três séries justificam a desconfiança de qual o verdadeiro propósito de seu ensino, afinal, uma aula semanal é insuficiente para que se trabalhe, minimamente, a filosofia. Então, questiona-se, de que filosofia se pode falar quando o assunto tem relação com a legislação, isto é, qual a forma em que este componente curricular está presente no ambiente escolar?

Com a nova Lei sobre o Ensino Médio (Lei n 13.415), de 2017, há muitas dúvidas sobre o sentido da filosofia no ensino médio. Afinal, seu status permanecerá ou não como disciplina, dado que se for por meio de tema transversal, sabe-se que, em última instância, a supressão da filosofia estará, mais uma vez, em questão. A limitação de espaço que o ensino de filosofia teve mesmo com a obrigatoriedade determinada pela Lei 11.684/2008 acaba de ser erradicada, uma vez que, não só o ensino de filosofia, mas sim, todo o ensino médio do país passou por uma drástica mudança. A Reforma do Ensino Médio, intitulado pelos governantes de Novo Ensino Médio, agora passa a vigorar regida pela Lei ${ }^{\circ} 13.415 / 2017$, esta por sua vez altera a Lei no 9.394/96, a Lei de Diretrizes e Bases da Educação Nacional (LDB), e institui a Política de Fomento à Implementação de Escolas de Ensino Médio em Tempo Integral. Este 


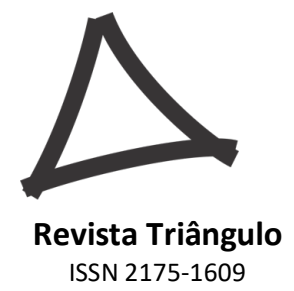

projeto foi submetido ao Senado Federal como Medida Provisória (MP) n n 746 de 22/09/16, e por mais penoso que seja para a educação, a aprovação aconteceu rapidamente, sem discussão com a sociedade. É evidente que a equipe gestora do Ministério da Educação argumenta que a discussão ocorre há mais de vinte anos, no entanto, é fácil demonstrar a fragilidade deste argumento, justamente pelo fato de que esta proposta é nova e não foi discutida com a sociedade. Assim, é improvável que se alcance êxito em uma proposta que não tenha tido o seu nascedouro na escola ou por meio de seus protagonistas.

No que se refere aos pontos específicos para o ensino de filosofia, a Lei 13.415/2017 atribui à Base Nacional Comum Curricular os aspectos de obrigatoriedade da disciplina de filosofia. De modo a especificar a situação da filosofia neste contexto, apresenta-se o artigo $n^{\circ}$ 35 e o inciso 2 que trata das questões pertinentes a nova configuração para o ensino de filosofia.

Art. 35-A. A Base Nacional Comum Curricular definirá direitos e objetivos de aprendizagem do ensino médio, conforme diretrizes do Conselho Nacional de Educação, nas seguintes áreas do conhecimento: I - linguagens e suas tecnologias; II - matemática e suas tecnologias; III - ciências da natureza e suas tecnologias; IV ciências humanas e sociais aplicadas. § 2o A Base Nacional Comum Curricular referente ao ensino médio incluirá obrigatoriamente estudos e práticas de educação física, arte, sociologia e filosofia. (BRASIL, 2017, p. 1)

Está posta a mudança para o ensino de filosofia, dado que ser incluído como "estudos e práticas" parece suficiente para que seja suprimida como disciplina. Se a filosofia não está prevista como disciplina, isto significa que a exigência para se trabalhar com ela está também em questão, isto é, qual a formação adequada para se trabalhar com estudos e práticas que incluam a filosofia? Será necessário o curso de Licenciatura? Qual o impacto desta nova legislação para os cursos de formação de filosofia no país? Ainda não há elementos para avaliar estes aspectos, no entanto, de pronto é possível reconhecer que a legislação não demanda aprimoramento ou aprofundamento da filosofia no ensino médio como campo do conhecimento, o que é lamentável para a educação básica.

Estudos que envolvem a compreensão da realidade e seu devido aprofundamento, nas diversas esferas, como é o caso da política, da ética, da estética, temas caros ao ensino de filosofia, que propiciam um conhecimento mais amplo e aprofundado da cultura parecem estar deslocados dos interesses da Base Nacional Comum Curricular. Assim, na argumentação de Mendonça (2011), sobre a importância do vetor da cultura por ocasião das discussões em torno do ensino de filosofia no Estado de São Paulo, na construção do Currículo ainda vigente, "O tema da cultura, nas suas diversas manifestações, é o pano de fundo da Proposta Curricular. O 


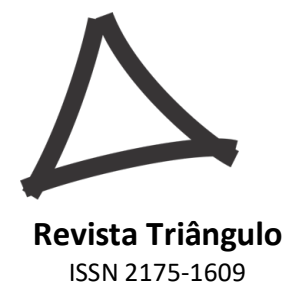

tema está presente com ênfase em elementos da vida social, na construção da cidadania consciente" (MENDONÇA, 2011, p. 139).

O específico da filosofia é o trabalho com o conceito, evidente que na perspectiva de Deleuze \& Guatarri (1992). A filosofia, como uma das três potências do pensamento, distinguese por criar conceitos, enquanto a arte e a ciência criam outros produtos de pensamento. Podese defini-la como a atividade de criação de conceitos, afinal:

[...] O filósofo é o amigo do conceito, ele é conceito em potência. Quer dizer que a filosofia não é uma simples arte de formar, de inventar ou de fabricar conceitos, pois os conceitos não são necessariamente formas, achados ou produtos. A filosofia, mais rigorosamente, é a disciplina que consiste em criar conceitos /.../ Criar conceitos sempre novos, é o objeto da filosofia. É porque o conceito precisa ser criado que ele remete ao filósofo como aquele que o tem em potência, ou que tem sua potência e sua competência /.../ Os conceitos não nos esperam inteiramente feitos, como corpos celestes. Não há céu para os conceitos. Eles devem ser inventados, fabricados ou antes criados, e não seriam nada sem a assinatura daqueles que os criam /.../ Que valeria um filósofo do qual se pudesse dizer: ele não criou um conceito, ele não criou seus conceitos? (DELEUZE; GUATTARI, 1992, p. 13-14)

Gallo (2006) afirma que a partir da noção de conceito posta por Deleuze e Guattari, a filosofia não é apenas um conjunto de conhecimentos criados historicamente, mas, sobretudo, uma atividade criativa, na medida em que o filósofo, encarnado e vivendo num mundo concreto, enfrenta problemas vitais, mergulhado no caos e na busca da criatividade que lhe permite inventar conceitos que ajudam a dar uma forma racional ao problema vivido, podendo assim encontrar soluções. E a história da filosofia, mais do que o inventário cronológico das soluções, é como que um arsenal, um repositório dos conceitos criados, que podem ou não servir como ferramentas, instrumentos para nosso próprio pensamento.

Cabe observar que a tarefa de pensar a filosofia como criação de conceitos para o nível médio é desafiadora, seja para a formação de professores, seja, sobretudo, pelas condições de escrita de estudantes deste nível de ensino. Diferente desta vertente de criação de conceitos, Aristóteles constituiu-se o pensador base de uma pesquisa mais ampla que aglutina este manuscrito. Assim, considerando o Currículo do Estado de São Paulo, que inclui a ética aristotélica, selecionaram-se três virtudes, quais sejam, a amizade, a justiça e a liberdade como base para a formulação dos instrumentos da pesquisa empírica, para conhecer, com professores e alunos, quais suas percepções sobre um aspecto do currículo e, por certo, da própria fílosofia. Passa-se a apresentar aspectos do pensamento do estagirita, sobretudo as três virtudes elencadas. 


\section{Revista Triângulo}

ISSN 2175-1609

Conceber a ética para o filósofo Aristóteles é uma tarefa árdua no que se refere a sua singularidade e a sua especificidade, dado que sua concepção para esta ação se faz de modo peculiar. Para Aristóteles, a ética é parte da ciência política, que por sua vez objetiva determinar qual é o bem supremo para as criaturas humanas, por sinal a felicidade, ou eudaimonia, que por sua vez é a finalidade da vida humana. Afirma-se, portanto, que na ética aristotélica o homem precisa viver de maneira a conquistar o bem estar que pode ser compreendido como bem viver. Os homens devem se respeitar na vida social, por conseguinte de maneira ética. No que se refere às virtudes descritas na ética aristotélica, vale salientar que, nesta pesquisa estão em foco apenas três delas: a amizade, a justiça e a liberdade.

A discussão sobre justiça ou sobre qualquer virtude no pensamento de Aristóteles ou em qualquer filósofo demanda a apresentação do conceito, para que de posse deste se possa dialogar acerca do agir ético. Em sua obra Ética a Nicômacos, o estagirita trata da justiça relacionando-a ou promovendo paralelo com a injustiça de modo a enfatizar a sua essência de ação. Neste caso, Aristóteles promove a discussão desta temática analisando ações que se relacionam com a justiça ou com a injustiça, tendo como elemento base a identificação do meio termo para cada situação, sendo ela justa ou não, dentro de suas concepções.

[...] todos os homens entendem por justiça aquela disposição de caráter que torna as pessoas propensas a fazer o que é justo, que as faz agir justamente e desejar o que é justo; e do mesmo modo, por injustiça se entende a disposição que as leva a agir injustamente e a desejar o que é injusto. (ARISTÓTELES, 1979, p. 121)

Atrelado à definição de justiça ou injustiça, do justo ou injusto, é necessário focar na natureza desta virtude, dado que para Aristóteles o indivíduo é responsável por sua ação, logo, ele deve ser detentor ou conhecedor daquilo que definimos como ato voluntário e involuntário, da escolha e da deliberação. A retidão e o agir correto, pautados em um meio termo, é por deveras difícil como aponta o filósofo. No mundo, as pessoas são colocadas à prova a todo momento, de modo que, o seu agir justo ou injusto está constantemente sendo tratado de forma ambígua. No ambiente escolar, os problemas relativos à ação justiça ou injusta são tão complexos quanto o entendimento do texto aristotélico.

A virtude da justiça requer que o homem ao agir tenha o discernimento de se ponderar também para com a virtude da liberdade. Ser justo e praticar a justiça estão relacionados ao seu posicionamento frente à liberdade. Compreender a virtude da liberdade na concepção de Aristóteles se faz necessário para compreender, de antemão, que para o filósofo o homem 


\section{Revista Triângulo}

ISSN 2175-1609

possui a capacidade de optar entre as diversas alternativas que a vida lhe oferece. $\mathrm{O}$ estagirita inicia a discussão sobre a liberdade da seguinte forma:

[...] Aparentemente ela é a observância do meio termo em relação a riqueza, pois as pessoas liberais são louvadas não a propósito de assuntos militares, nem daqueles a respeito dos quais as pessoas moderadas são louvadas, nem de decisões judiciais, mas em relação a dar e obter riquezas - especialmente em respeito de dá-las. (ARISTÓTELES, 2001, p. 71).

O filósofo trata da liberdade promovendo uma discussão entre a prodigalidade e a avareza, afirmando que ambas se referem ao excesso e a falta em relação ao uso da riqueza. $\mathrm{O}$ uso das coisas de forma apropriada é a discussão que promove Aristóteles na continuidade de sua explanação acerca da virtude liberdade. Para o estagirita, as pessoas que melhor fazem uso das coisas são as liberais. Por liberal se deve ter o entendimento de quem faz uso da razão e, portanto, age de forma intencional e livre na busca da excelência moral. Para ele, quem melhor usa as coisas são os portadores da excelência moral, e confirmando suas palavras “[...] os bens, portanto, serão melhores usados pelas pessoas dotadas da forma de excelência moral relacionadas com a riqueza... ora gastar e dar parece caracterizar o uso da riqueza" (ARISTÓTELES, 2001, p. 71). Faz-se necessário conceituar a liberdade. Argumenta Aristóteles (2001, p. 72) "[...] A palavra liberdade é usada tendo em vista o vulto das posses de uma pessoa, pois a liberdade não está no grande número de presentes, e sim na disposição da alma de quem dá, e isto é proporcional às posses de quem dá".

A liberdade como ética é uma ação que requer cautela, é preciso estar pleno de sua razão. As virtudes na concepção de Aristóteles visam a um propósito, o de alcançar a eudaimonia, assim, amizade, justiça e liberdade devem estar presentes no agir virtuoso, para que, assim, o homem possa alcançar a felicidade.

É interessante observar, embora não se possam desenvolver as virtudes conforme seria desejável, considerando os limites de um artigo, que a amizade, a justiça e a liberdade estão, seguramente, no ambiente escolar. Não se trata aqui de anacronismo e, por isto, o sentido empreendido por Aristóteles está longe de refletir o que temos na escola por diversas razões. Mesmo assim, a aproximação de conceitos de um autor de um tempo histórico distinto do atual é sempre motivo de preocupação e deixamos claro que não se pretendeu, na pesquisa, afirmar que Aristóteles seria ferramenta suficiente para a compreensão dos problemas sociais da escola 


\section{Revista Triângulo}

ISSN 2175-1609

de hoje. Passa-se, a seguir, para a exposição do método, dos instrumentos de pesquisa, da categorização e discussão dos resultados.

\section{MATERIAIS E MÉTODOS}

O método utilizado nesta investigação consistiu em exame qualitativo, sem desprezar as informações quantitativas, isto é, coletou dados e, para tanto fez uso de três diferentes instrumentos de coletas de dados, quais sejam: questionários a docentes e discentes por meio da ferramenta online survio, entrevista com docentes e grupo focal com discentes. No que se refere aos lócus de pesquisa, este se refere a cinco escolas da Diretoria de Ensino Campinas Leste, sendo duas delas Escolas de Tempo Integral e três de ensino regular. A pesquisa fora realizada com sujeitos específicos, sendo eles alunos da $3^{\text {a }}$ série do ensino médio, a considerar para o questionário uma população de cento e sessenta e oito alunos e, para o grupo focal doze alunos sendo seis do ensino médio de tempo integral e seis do ensino médio regular, a entrevista fora realizada com um docente de cada tipo de escola.

Trata-se de pesquisa diferente das realizadas no campo da filosofia, seja em relação a temáticas que envolvem a filosofia da educação ou mesmo o ensino de filosofia, de modo a sugerir a necessidade de estudos empíricos para este importante campo do conhecimento.

Partiu-se, portanto, para a análise dos resultados da pesquisa empírica que se apropriou de três diferentes instrumentos de coleta de dados, sendo eles: a aplicação de questionários a docentes e discentes das escolas lócus desta pesquisa, entrevista a dois docentes sendo um representante de cada modalidade de ensino citada e, ainda, a realização de grupo focal em duas unidades escolares, também uma de cada modalidade de ensino. No que se refere à categorização, foram os dados empíricos que geraram a sistematização dos temas, a partir de uma maior incidência, de modo que o resultado gerou as categorias: (i) $\mathrm{O}$ ensino de filosofia; (ii) A formação ética aristotélica; (iii) $\mathrm{O}$ agir ético e o meio termo; (iv) $\mathrm{O}$ antagonismo entre formação e postura ética; (v) A concepção da virtude da amizade; (vi) A concepção da virtude de liberdade; (vii) A concepção da virtude de justiça. As categorias surgiram do material coletado, isto é, da percepção dos sujeitos de pesquisa sobre o ensino de filosofia, estudantes e professores. 
Revista Triângulo

ISSN 2175-1609

\section{ANÁLISE DOS DADOS E RESULTADOS}

Para este artigo, não será possível desenvolver todas as categorias com as falas dos sujeitos, de modo que se optou por tratar das categorias: o ensino de filosofia e o antagonismo entre formação e postura ética. A filosofia no curso do ensino médio foi vislumbrada pelos docentes e discentes da rede estadual como uma disciplina de grande valia para a formação do cidadão. Foi unânime a ênfase à sua importância na construção de habilidades intelectuais e de formação crítica, fatos esses que corroboram com as descrições de Cartolano (1985, p. 65) apontadas para a filosofia: "A filosofia constitui o complemento necessário à formação do espírito, como instrumento que é, da grande arte do raciocínio. Desenvolvendo o espírito crítico, a capacidade de reflexão pessoal, o senso de liberdade intelectual”. O quadro I, intitulado $\mathrm{O}$ ensino de filosofia nas escolas estaduais lócus, sobre a categoria ensino de filosofia, resume sua importância.

Quadro I - O ensino de filosofia nas escolas estaduais lócus

\begin{tabular}{|l|l|l|l|l|}
\hline Categoria: Ensino de filosofia & \multicolumn{2}{|c|}{ Docentes } & \multicolumn{2}{c|}{ Discentes } \\
\hline Questionamento & Concordam & Discordam & Concordam & Discordam \\
\hline Desenvolve a criticidade & $80.00 \%$ & $20.00 \%$ & $88.10 \%$ & $11.90 \%$ \\
\hline Pautado na ética & $100.00 \%$ & $0.00 \%$ & $82.75 \%$ & $17.25 \%$ \\
\hline Desenvolve de Habilidades & $100.00 \%$ & $0.00 \%$ & $88.10 \%$ & $11.90 \%$ \\
\hline Existe adequação currículo & $80.00 \%$ & $20.00 \%$ & ------- & -------- \\
\hline
\end{tabular}

Fonte: Quadro construído pelos pesquisadores, a partir de dados obtidos pelo Survio

Foi possível identificar que o ensino de filosofia na percepção dos alunos tem grande importância e significado, além de contribuição em seu processo de formação e de construção do conhecimento. É dado à filosofia o crédito que conduzir o estudante à construção do conhecimento.

Ao longo da pesquisa empírica identificou-se que há grande aversão à postura e as imposições negativas para com o ensino de filosofia, bem como para a desvalorização e o descrédito que é dado à disciplina. Mas, mesmo sendo uma contradição o fato de que os discentes e os docentes nas escolas deem crédito à disciplina de filosofia, o governo age de 


\section{Revista Triângulo}

ISSN 2175-1609

modo a ir na contramão desta valorização dada pelos protagonistas da educação. Corrobora com esta fala o professor Silvio Gallo (2003, p. 30), quando "[...] alerta que se vive em uma sociedade de controle, e o ensino de filosofia pode ser usado também como um instrumento de controle". Afinal, qual o interesse do estado para fazer cidadãos pensantes, críticos, reflexivos?

No que se refere à temática ética, em especial a de Aristóteles, que versa sobre o agir ético pautado nas virtudes, qual a sua percepção sobre a questão de os alunos estabelecerem e ou aceitarem a ética pautada nas virtudes, eles possuem esta percepção?

\footnotetext{
Ética para os alunos não têm a visão de que a ética pautada nas virtudes, ética para eles é muito do senso comum, logo, a linguagem conceitual não é deste pensador. (Entrevistado I)

O caderno do aluno traz uma tabela das virtudes Aristotélicas, com o extremo, a falta, o excesso e o caminho do meio termo, logo esta maneira didática e pedagógica adotada e posta ou imposta (para alguns a proposta curricular é imposta) permite com que eles vislumbrem bem esta questão e, ao meu ver, é de fácil compreensão para eles verem a ética como uma questão pautada nas virtudes, em especial a da justiça. (Entrevistado II)
}

A pergunta feita e as respostas dos entrevistas I e II evidenciam a apropriação tanto conceitual, no caso da ética, quando de Aristóteles. Ao longo do desenvolvimento da pesquisa, no que se refere a ética aristotélica em sala de aula e o desenvolvimento da concepção e aplicabilidade de suas virtudes, observou-se o fato de os alunos assumirem a necessidade de viver conforme as virtudes aristotélicas significam, em si, que vivem eticamente? Não foi o que se observou, sobretudo, na aplicação do instrumento grupo focal.

Ao que parece a apresentação da ética aristotélica conforme apresentado no caderno do aluno, onde é possível vislumbrar a virtude pelo meio termo, sua deficiência e o seu excesso, facilitam a compreensão dos alunos e, eles a classificam como apropriada para a formação da ética aristotélica. É evidente e plausível que se compreendam as ações docentes, bem como a transmissão de conceitos por parte deles e sua respectiva influência na formação de conceitos dos alunos; afinal, o papel da escola é também o de formar conceitos no universo das ciências e também da filosofia.

A pesquisa empírica identificou que as virtudes da amizade, da justiça e da liberdade, estão presentes no contexto escolar da escola. Os alunos a possuem, a identificam, mas muitas vezes esta ação não está para além dos muros da escola, ou seja, a sociedade não age de maneira condizente com as virtudes aristotélicas. Não havia expectativa para que isto fosse algo da "natureza", isto é, que a sociedade vivesse preceitos aristotélicos, no entanto, justamente pelo 


\section{Revista Triângulo}

ISSN 2175-1609

fato de que se trata de autor que tem seus conteúdos previstos no Currículo do Estado de São Paulo, então, neste caso, especulou-se sobre a possível compreensão e ação ética correspondente por parte dos estudantes e professores nas escolas. No grupo focal houve falas neste sentido, por parte de alguns alunos, demonstrando insatisfação social com a vivência por virtudes na sociedade, salvaguardando as relações no espaço escolar. Mesmo assim, observouse comportamentos, por vezes, desrespeitosos entre os colegas, então, em que pese o discurso de agir virtuoso no ambiente escolar, ele não ocorre de forma romântica, mas, contextualizada, abarcando, também, noções de inimizade e de injustiça.

Ao longo da análise dos resultados, vislumbrou-se que a amizade, na percepção dos discentes e nas afirmações dos docentes quando analisam a postura dos discentes, não tende para a concepção aristotélica, mas sim, para a compreensão de uma amizade utilitária. Este descompasso entre teoria e o agir é muito interessante e parece refletir a sociedade em que estamos inseridos, a sociedade capitalista, do uso de recursos e de pessoas. Não caberia neste estudo o exame do sistema capitalista e da influência do ter sobre o ser, no entanto, impossível não tocar neste assunto quando o assunto é a ética. Talvez também por isto Aristóteles não tenha sido autor que fez corresponder a sua teoria às ações humanas, na hipótese de que o mundo de hoje é não aristotélico por excelência e nem poderia ser aristotélico; afinal, que formação promove a escola em relação à cultura, em relação às virtudes, em relação à lógica ou mesmo à metafísica?

Com relação à virtude da justiça os dados empíricos revelam algumas divergências de percepção. Na teoria, os discentes afirmam que a concepção de Aristóteles para com a virtude da justiça é a mais indicada, no entanto, quando se coloca que a justiça está em promover o bem para quem nos faz o bem e o mal para quem nos faz o mal, há uma grande aceitação para com esta concepção, o que diverge da concepção aristotélica.

Quando se falou da virtude da justiça e elencou-se como um dos pontos chave para a discussão desta temática as leis, é preciso estar atentos àquilo que a legislação determina para que se logre a justiça. Aristóteles (2001, p. 92) apresenta duas colocações acerca desta relação: “[...] as leis visam ao interesse comum de todas as pessoas", e, “[...] os atos justos são aqueles que tendem a produzir e a preservar a felicidade, e os elementos que a compõem, para a comunidade política". Tendo o processo de aprendizagem focado em objetivos de uma formação plena e coesa, tem sua ação a partir da ética desde que, o ambiente escolar promova 


\section{Revista Triângulo}

ISSN 2175-1609

a ação virtuosa nos cidadãos em formação, ou seja, evidenciou-se a busca pela formação do homem virtuoso, amparados na citação de Aristóteles (1982, p. 541) que diz: “Os homens tornam-se bons e virtuosos devido a três atores, e estes são a natureza, o hábito e a razão. Ora, a razão e a inteligência são os fins de nossa natureza. Por isso é necessário preparar-lhes a formação e o cultivo dos hábitos".

A educação como hábito foi foco das discussões e apontamentos dos docentes envolvidos nesta pesquisa. Grande parte deles aceita a questão do hábito na educação, outra parte afirma acreditar que não é somente pelo hábito que se pode formar e construir um conceito, bem como ressignificá-lo. Para este docente, o ato é o de ensinar mesmo, dada a carência que os mesmos trazem para com a formação moral e ética, em princípio base da educação familiar.

O ponto de destaque desta investigação diz respeito ao antagonismo observado nos discentes quanto à postura entre teoria e prática, quarta categoria de análise. A pesquisa revelou que este antagonismo de fato existe e os discentes afirmam que a razão pelo qual esta ação existe está no fato de que há uma distinção entre o racional e o sentimental. Eles optam por agir pelo sentimento e não pelo racional, como deveriam agir, frente às questões que são cabíveis aos valores morais e éticos e das atitudes voltadas a esses valores. Assim, de modo a ratificar os fatos que evidenciam as questões voltadas para o antagonismo entre formação e agir para com a ética aristotélica, seguem os dados empíricos. É evidente que o entendimento dos discentes sobre sentimentos não se resumo naquilo que pensou Aristóteles e isto não é diferente em se tratando da racionalidade. Para os jovens de hoje, a razão é instrumental e mercadológica e para o estagirita, a razão alcança plenitude de realização de virtudes.

Ao se pensar nas questões da relação entre o ato de ser detentor do conhecimento e do agir de acordo com este conhecimento adquirido, fato este, que por sua vez se volta para o problema desta pesquisa, na busca da compreensão de um por que, mesmo tendo a concepção de ética, o agir é contrário, indagou-se aos discentes sujeitos desta pesquisa: "qual seria a explicação que justifique o fato de que, em alguns momentos, mesmo sendo conhecedores da ética aristotélica (que se pauta nas virtudes) não agimos com a ética deste filósofo". Para esta questão os discentes do grupo focal afirmam:

A1: Em certos momentos deixamos de lado o conhecimento, por algum motivo, deixamos de ser racional e agimos pelo impulso, sem qualquer ética, a comunidade, as situações e as pessoas, muitas vezes nos levam a ações de extrema incoerência, sem ética, sem valores. 
Revista Triângulo ISSN 2175-1609
A2: O agir é algo de momento, e, não tenho ainda a capacidade de me posicionar de acordo com aquilo que aprendi, minha ação é diante daquilo que acho certo ou não, e, muitas vezes, não passa por questões éticas, mas sim, de ser movido por um sentimento.

A3: No respeito próprio, muitas vezes nos diminuímos por causa de terceiros, $e$ também em outros pontos.

A4: Talvez alguém que esteja passando algum tipo de privação ou necessidade irá agir contra seus princípios éticos mesmo tendo o conhecimento, na vida cada momento tem uma necessidade especifica, não podemos julgar muito menos as pessoas que não tenham uma ação virtuosa quando estejam carentes de algo, que tenham sido agredidas ou violentadas. Mas há também aqueles que optem por agir sem ética, mesmo sendo conhecedores porque são mal caráter.

A5: Acredito que em muitas situações o fator emocional é o que não permite o agir para com a ética de Aristóteles, a virtude de Aristóteles é bem racional ao meu ver $e$, quando os fatores emocionais estão latentes, muitas pessoas agem comandados pela emoção e não pela razão.

A6: É simples. Conhecer não é ser, pois essa é a ética do ponto de vista dele e não de todos.

D1: Eu acho que isso acontece porque agimos por impulso e sempre, a maioria das pessoas acham melhor resolver a situação pela agressão, pela ignorância, e não pela razão e pelo conhecimento adquirido.

D5: Nem sempre seguimos as virtudes de Aristóteles, tudo depende do agir do outro, acho que o mundo hoje é meio que uma selva, e ainda há muitos irracionais na espécie humana, e para com essas pessoas não tem como agir com ética.

D6: Acredito que o homem age de acordo com os seus impulsos, as pessoas mais racionais agem com mais coerência, as mais emocionais agem por impulso e respondem as situações de maneira mais voluntária e fisica. Este antagonismo gera a violência fisica e verbal entre as pessoas.

É muito interessante observar a fala que aponta para uma ação não racional. A utilização do grupo focal foi intensa e potente para a reflexão filosófica. À medida em que um sujeito afirmava não agir racionalmente, outro inseria uma moderação sobre a importância da ação racional e não de forma dogmática, mas, justamente, de forma filosófica, isto é, inserindo pergunta ao interlocutor. Observe-se o quadro II, intitulado Característica do antagonismo entre formação e agir ético, que trata da categoria Antagonismo entre formação e agir ético.

\section{Quadro II - Característica do antagonismo entre formação e agir ético}

\begin{tabular}{|l|l|l|l|l|}
\hline Categoria: Antagonismo entre formação e agir ético \\
\hline & \multicolumn{2}{|c|}{ Docentes } & \multicolumn{2}{c|}{ Discentes } \\
\hline Questionamento & Concorda & Discordam & Concorda & Discorda \\
\hline Relação entre formação e agir ético & $100,00 \%$ & $0,00 \%$ & $88,75 \%$ & $11,25 \%$ \\
\hline Educação provê ao cidadão ações & $100,00 \%$ & $0,00 \%$ & $85,10 \%$ & $14,90 \%$ \\
\hline
\end{tabular}

Fonte: Quadro construído pelos pesquisadores, a partir de dados obtidos pelo Survio 


\section{Revista Triângulo}

ISSN 2175-1609

É curioso notar que entre os docentes, houve unanimidade em relação à formação e agir ético e o fato de que a educação provê ao cidadão ações virtuosas. Os alunos, instados a responder a mesma questão, não encontraram unanimidade. Este resultado demonstra que a aplicação dos instrumentos com professores e alunos foi acertada, afinal, nem sempre a visão de um tipo de sujeito é ampla para significar o que ocorre no ambiente escolar. A afirmação dos alunos de que há descompasso entre o que provê a educação aos cidadãos, em relação às ações virtuosas, parece mais representativa do que a concordância dos professores. Isto não significa que um tenha razão e outro não, mas, justamente, o conflito e o reforço do antagonismo entre o saber o viver ético.

É um fato evidente e apontado como elemento problematizador desta pesquisa o antagonismo entre a formação ética e o agir ético, logo, na busca por respostas que possam responder a esta distorção, perguntou-se aos discentes sujeitos desta pesquisa: "qual a sua percepção, visão ou compreensão sobre o antagonismo entre a formação ética e o agir ético?” Diante desta questão obtivemos as seguintes respostas dos alunos:

A1: Tem muita diferença em saber e agir. Sabemos e temos conhecimento de muitas coisas, mas por impulso, acabamos não agindo de acordo.

A2: Vai ser sempre diferente eu acho até que eu tenha maturidade suficiente.

A3: Na minha percepção tudo depende da situação, vejo que mesmo com a base da ética em mente, muitas vezes não conseguimos praticá-la porque outro não sabe sequer o que está falando, não se é possivel lidar dentro da ética de Aristóteles se, em minha comunidade, as pessoas sequer sabem o que significa esta palavra.

A4: Creio que as pessoas são diferentes e sempre colocam em prática o que aprendem, mas outros não, pois ética ao meu ver, ou melhor, o agir virtuoso da ética está voltado ao caráter de cada um. Ter ética para mim se resume em ter caráter, $e$ isso se constrói quando somos educados em casa e aprimoramos na escola.

A5: Ao meu ver, precisamos sim de uma formação ética, mas isso não garante o agir ético dentro de princípios, talvez demande tempo, o ser humano é muito passional, talvez isso faça dele um ser que não tem uma ação ou agir estável.

A6: Continuo me baseando na colocação do Conhecer não é ser, ou seja, o conhecimento de algo pode influenciar na forma de agir das pessoas, mas isso não significa que obrigatoriamente vá acontecer ou influenciar, depende de vários fatores entre razão e emoção.

D1: Ter o conhecimento nos forma e informa, se vou agir ou não dentro dos meus conhecimentos é algo bem diferentes, para cada caso um caso, não posso ser ético com quem me ofende ou agride verbalmente ou fisicamente, isso acredito explicar o antagonismo entre formação e agir ético, sou ético se a situação me conduz ao ser ético, caso contrário respondo aos meus instintos.

D5: O antagonismo é produto de ideias erradas sobre a ética de Aristóteles, mas infelizmente as pessoas seguem o contrário da ética em muitos casos, acho que de fato elas não conhecem a ética de Aristóteles, ou melhor, não foi compreendida de fato.

D6: Eu ter o conhecimento da ética me forma como ser humano, mas as condições do meio em que eu esteja inserido me faz agir em defesa de mim mesmo, e em defesa daqueles que eu convivo, então acho que formação e agir sempre serão ações 
distintas, eu posso conhecer, mas o que eu tenho como ação e postura não depende só do meu conhecimento, mas do meu entorno, das situações do momento, da qualidade de vida, se eu preciso me defender ou não.

Ao analisar as respostas dos alunos, percebe-se que a concepção deles frente ao antagonismo entre conhecimento e agir para com a ética, resume-se na ação do dia a dia, ação esta que está atrelada ao seu entorno, as condições de sua vivência, de sua relação para com os demais integrantes de sua comunidade, além da diferença de concepção e base de educação familiar que cada um apresenta de modo bem peculiar.

Evidenciar a questão do antagonismo percebido nos discentes, no que se refere às suas práticas, frente às questões que envolvem valores éticos e morais, requer vivenciar ou expor os alunos à questões em que possam demonstrar de fato esta possibilidade de antagonismo. Deste modo, foi proposto a eles que se posicionassem acerca da seguinte situação problema: Durante um debate em sala de aula dois alunos não concordam com o ponto de vista um do outro. $\mathrm{O}$ professor tenta dialogar pedindo as partes que busquem a compreensão e o meio termo para que a situação seja justa para ambos. Neste momento os envolvidos partem para a agressão verbal e física. É certo que recebemos ensinamentos sobre virtudes morais e éticas de base familiar e na escola, mas o que moveu os estudantes neste caso?

$\mathrm{Na}$ sua concepção diante deste antagonismo (tenho base educacional sobre valores morais e não as executo parto para a agressão física e verbal), agir desta maneira é uma ação: Neste caso, 7,5\% dos alunos consideram que a postura descrita na citação foi normal, todos devem agir movidos por seus sentimentos; 7,5\% qualificam como normal, todos devem agir movidos apenas pela razão, no entanto, $31,25 \%$ afirmam que não consideram normal nem fora dos padrões de normalidade, consideram fora de meus princípios; para 43,75\% a postura dos alunos é incorreta. Ele se deixou levar pelos sentimentos e não pelo racional e ainda, para 10,0\% dos alunos a postura descrita na situação problema é incorreta. Ele se deixou levar pela razão e não pelos sentimentos.

A análise dos resultados apresentados para esta questão remete ao posicionamento de Thornton (1982), que coloca em xeque-mate a relação entre a concepção e as concepções teóricas e o agir propriamente dito:

[...] Por mais perfeita que seja a lógica, a sabedoria teórica não pode nos ajudar quando se trata de saber como agir. Aristóteles diferencia a razão pelo seu fim, pela causa final a que ela se destina. Na razão teórica precisamos saber a conclusão, o fim 
a que queremos chegar, enquanto na razão prática precisamos saber o problema que queremos resolver. A conclusão da razão teórica é uma verdade. O que pensamos é verdadeiro. A conclusão da razão prática é uma indicação do melhor caminho para o bem, nosso e dos outros. O que pensamos é bom. (THORNTON, 1982, p.63)

Neste caso, acredita-se que a ação não fora conduzida por uma ação consciente de uma pessoa que sabia a que fim queria chegar. Percebe-se uma ação involuntária regida por um sentimento momentâneo ou de princípios distintos. As repostas mostram, no entanto, que o percentual de 31,25\% não considera nem normal nem fora dos padrões. Demonstra literalmente o antagonismo e certa aceitação da conduta do jovem, uma vez que, esta ação fora mediada por uma distorção entre a razão teórica e a razão prática. Será mesmo que os envolvidos sabiam a que fim queriam chegar? Será que de fato eles sabiam resolver o problema foco da discussão? Contudo, diante da situação problema, fica evidente que a ação dos jovens foi mediada pelos sentimentos e não pela razão, e, neste caso, agir regido ou comandado pelos sentimentos não é a melhor opção. Vejamos o que Aristóteles escreve na obra Metafísica "Para orientar o agir também não nos servem os sentimentos. As sensações não nos dizem o porquê” (Aristóteles, 1979, p. 981).

Thiry-Cherques (2003), parafraseando Aristóteles, em Ética a Nicômacos, realiza uma discussão acerca desta distinção do agir humano frente às questões da razão e do sentimento:

[...] Para Aristóteles, a alma é tanto racional como não-racional. Por sua vez, a porção não-racional da alma é parte irracional (vegetativa) e parte obediente à razão (apetitiva, relativa aos desejos). As virtudes da alma racional são dianoéticas, são as virtudes do intelecto. As virtudes da alma não racional apetitiva são as virtudes éticas, as virtudes do controle dos apetites. (THIRY-CHERQUES, 2003, p. 3)

Evidencia-se na fala de Thiry-Cherques (2003), ao parafrasear Aristóteles, a importância das virtudes e da ação perante elas. Mais uma vez, fica claro e evidente que o antagonismo se fez evidente diante do fato de que os ensinamentos de educação familiar e escolar sobre os valores morais e éticos não foram efetivos a ponto de evitar o desfecho da situação problema, ou seja, a razão e a teoria perdem para o sentimento e o impulso. Seguindo a linha de busca por respostas por esta ação de antagonismo, questionou-se aos discentes sobre os possíveis meios que possam culminar e interferir em nossas ações e maneira de agir frente às mais diversas situações. Assim, os participantes da pesquisa foram provocados a pensar e a responder sobre: somos diariamente expostos a situações onde temos que tomar decisões e estas por sua vez devem mesclar e considerar o racional e o não racional. Qual é a sua percepção 


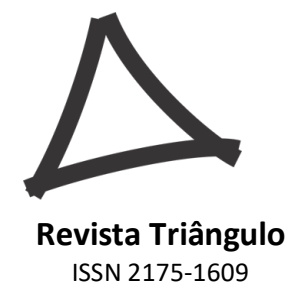

ou o seu ponto de vista sobre a afirmação: A ação humana depende da combinação de todos os poderes da alma: percepção, imaginação, raciocínio e desejo. Qual é o seu grande de concordância para com a afirmação acima?

Para esta questão, 37,5\% dos alunos concordam plenamente com a citação, enquanto que $42,5 \%$ dos discentes concordam parcialmente, ao passo que, 20,0\% deles discordam da citação. A discussão dos resultados obtidos para esta questão requer que se atente e se retome a descrição da origem da ação, que Aristóteles apresenta em sua obra Ética a Nicômacos:

[...] A origem da ação (sua causa eficiente, e não final) é a escolha, e a origem da escolha está no desejo e no raciocínio dirigido a algum fim. É por isto que a escolha não pode existir sem a razão e o pensamento ou sem uma disposição moral, pois as boas e as más ações não podem existir sem a combinação de pensamento e caráter. (ARISTÓTELES, 2001, p. 114)

A revelação de que quase praticamente a metade dos sujeitos discentes desta pesquisa concorda parcialmente, acrescido com os $20 \%$ que discordam com a citação de que a ação humana depende da combinação de poderes da alma, releva e justifica o antagonismo entre a teoria e a prática observado no cotidiano escolar no que se refere à postura para com ao agir virtuoso. Mais uma vez, não é o conhecimento acadêmico, sistemático, conceitual a base do agir virtuoso, paradoxalmente.

$\mathrm{Na}$ busca pela ratificação das questões que envolvam o antagonismo na ação nos discentes, perguntou-se a eles. É evidente que existe um antagonismo entre a teoria e o agir ético e virtuoso proposto por Aristóteles. Recebemos ensinamentos sobre a ética aristotélica e o agir virtuoso, no entanto, agimos muitas vezes de maneira antagônica a esta teoria. Analise a citação:

O que nos faz agir é a alma, aquilo que nos anima. Para Aristóteles, a alma é tanto racional como não racional. Por sua vez, a porção não-racional da alma é parte irracional (vegetativa) e parte obediente à razão (apetitiva, relativa aos desejos). As virtudes da alma racional são dianoéticas, são as virtudes do intelecto. As virtudes da alma não racional apetitiva são as virtudes éticas, as virtudes do controle dos apetites (THIRY-CHERQUES, 2003, p. 3).

Sobre o fato de muitas vezes se age de maneira antagônica para com a teoria que se possuí acerca das questões que envolvam virtudes e valores morais, qual o seu grau de concordância para com a citação? Os resultados para esta pergunta revelam que $61,00 \%$ dos alunos concordam parcialmente, enquanto que, $35,25 \%$ concordam plenamente, $3,75 \%$ dos discentes discordam. 


\section{Revista Triângulo}

ISSN 2175-1609

De acordo com Thiry-Cherques (2003), parafraseando Aristóteles, a questão do agir frente às questões racionais e da alma: "Para orientar o agir também não nos servem os sentimentos. As sensações não nos dizem o porquê, e sem o porquê, sem o conhecimento das causas a ação não é razoável". Mais uma vez, os resultados confirmam que o antagonismo, observado nas escolas frente às questões que envolvem as virtudes na teoria e na prática, partem por uma questão que permeia e caminha pela ação voltada para os impulsos e para a não razão. Contudo, é preciso salientar e fazer evidente para os alunos, os ensinamentos de Aristóteles (2001, p. 59): “[...] os poderes nos são dados, mas cabe a nós combiná-los. Nós, os seres dotados de razão, somos responsáveis pelo que fazemos da nossa alma”.

Esta concepção é certamente o centro de controle que falta aos discentes, que requer retomada e discussões efetivas em sala de aula em prol de uma comunidade composta de sujeitos cujas ações e atitudes permeiam e sejam regidas pelo racional e pela sabedoria, e não pela discussão infundada e pela concepção de fazer o mal pelo mal, de agredir, de ofender sem motivos, de não buscar o meio termo, de não ser ou praticar as virtudes.

Mesmo considerando todas as ponderações entre o antagonismo teoria e prática, o ensino de filosofia nas escolas da rede estadual do ensino é visto como essencial para a formação dos cidadãos, em especial por possibilitar a sua formação intelectual e crítica e, utilizar esta formação para impor-se ou mostrar-se frente às questões impostas. A ética aristotélica está presente no Currículo oficial do Estado de São Paulo, no entanto, como afirmação dos docentes e discentes em especial, ela não é vislumbrada na totalidade dos integrantes da sociedade. O agir virtuoso, pautado na reta razão, ainda é uma ação a ser construída e executada com maior ênfase entre os membros da sociedade.

\section{CONSIDERAÇÕES FINAIS}

Se o problema desta investigação consistiu na pergunta: qual é a percepção de docentes e discentes de filosofia, da Diretoria de ensino Campinas Leste, acerca da ética aristotélica?, pode-se argumentar que as percepções dos sujeitos da pesquisa evidenciam conhecimento sobre o pensamento aristotélico, em especial sobre as virtudes da amizade, da justiça e da liberdade, no entanto, notou-se o antagonismo entre a teoria, isto é, os conhecimentos conceituais de Aristóteles e o agir moral, sobretudo além dos muros escolares. Se o interesse 


\section{Revista Triângulo}

ISSN 2175-1609

da investigação em conhecer o posicionamento de professores e estudantes sobre o pensamento aristotélico, como resultados, já expressos, singularizou a pesquisa, dado que a literatura já avançou sobremaneira sobre o ensino de filosofia na perspectiva de diferentes autores, é preciso considerar a importância de quem vivencia o ensino de filosofia. Por isto, a pesquisa empírica pode significar avanço para outras investigações do campo da filosofia em geral e de estudos sobre o ensino de filosofia, de forma particular.

Pela amostra, parcial, recortada, mas circunscrita à escola pública do município de Campinas, SP, pode-se argumentar que a forma que o ensino de filosofia tem sido trabalhado em sala de aula tem sido efetiva, mesmo considerando as adversidades e condições materiais que têm os professores para a docência em escola pública no Estado de São Paulo.

O estudo demonstrou ainda preocupação com as políticas públicas, em especial a nova Lei 13.415/2017 (BRASIL, 2017) que redesenhou o Ensino Médio brasileiro e que inseriu a filosofia ainda como componente obrigatório, no entanto, na Base Nacional Comum Curricular. É preciso garantir a presença da filosofia nos bancos escolares, no entanto, se esta presença não ocorre em condições satisfatórias para o exercício filosófico, talvez se deva pensar o uso da filosofia, por parte do poder público, como forma de controle social.

De forma precisa quanto à ética aristotélica, em relação ao agir moral, a escola deve propiciar espaço para a consolidação desses saberes? Por certo, mais do que saberes, a escola tem a prerrogativa de apresentar os conhecimentos consolidados ao longo da história e, de certo modo, os estudantes serão instados a agir sempre racionalmente, de modo a evitar o sofrimento ou mesmo o prazer. Retomando o pensamento de seu mestre Platão, Aristóteles, (2001, p. 37) afirma que "[...] é por causa do prazer que praticamos o mal e é por causa do sofrimento que deixamos de praticar o bem. Assim, devemos ser levados, de um modo ou de outro, desde a mais tenra infância a encontrar no prazer e no sofrimento o que é certo, pois, como observava Platão, nisso consiste a verdadeira educação".

Diante do contexto apresentado, espera-se que a escola seja um espaço de formação, que não preze e foque suas ações apenas em conteúdos programáticos específicos de disciplinas. A formação humana vai além de conteúdos e a importância da filosofia, igualmente, diz respeito a potencial para a transformação da vida de jovens do ensino médio.

O ambiente escolar é um espaço plural, de interesses diversos, no entanto, Aristóteles oferece um arcabouço teórico suficiente para que se busque uma formação para a excelência 


\section{Revista Triângulo}

ISSN 2175-1609

moral, uma formação que cultive virtudes como a amizade, a justiça e a liberdade na escola. Os professores estão preparados e dispostos a oferecer a melhor formação aos estudantes? E os estudantes, que são educados pela família, estão prontos para receber a educação escolar? Mesmo com o evidente descompasso entre a teoria aristotélica e as percepções de professores e de estudantes de escolas públicas de Campinas, é possível argumentar, com Aristóteles, que o homem é um animal racional e político, portanto, o ambiente escolar é o lugar propício para o contínuo desenvolvimento de virtudes para a vida social.

\section{REFERÊNCIAS}

ARISTÓTELES. Ética a Nicômacos. Tradução de Mário da Gama Kury. 4. ed. Brasília: Editora Universidade de Brasília, 2001.

Metafísica: livro 1 e livro 2; Ética a Nicômaco; Poética. Seleção de textos de José Américo Motta Pessanha. Tradução de Vincenso Cocco et al. São Paulo: Abril Cultural, 1979.

CARTOLANO, M. T. P. Filosofia no Ensino do $2^{\circ}$ grau. São Paulo: Cortez: Autores Associados. 1985.

CENCI, A. V. Aristóteles \& a educação. Belo Horizonte: Autêntica Editora, 2012.

DELEUZE, G.; GUATTARI, F. O que é a filosofia? Rio de Janeiro: Ed. 34, 1992.

FÁVERO, A. A.; CEPPAS, F.; GONTIJO, P. E.; GALLO, S.; KOAHN, W. O. O Ensino da Filosofia no Brasil: Um mapa das condições atuais. Cad. Cedes, Campinas, vol. 24, n. 64, p. 257-284, set./dez. 2004.

GALLO, Silvio; ASPIS, Renata Lima. Ensino de filosofia e cidadania nas "sociedades de controle": resistência e linhas de fuga. Pro-Posições, Campinas, v. 21, n. 1 (61), p. 89-105, jan./abr. 2010.

GALLO, S. A filosofia e seu ensino: conceito e transversalidade. ETHICA. Rio de janeiro, v.13, n.1, p.17-35, 2006.

Metodologia do Ensino de Filosofia - Uma Didática Para o Ensino Médio.

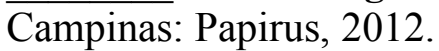

KOHAN, Walter (org.). Filosofia: Caminhos para seu Ensino. Rio de Janeiro: Ed. DP\&A, 2004. 
Revista Triângulo

ISSN 2175-1609

MAZAI, N.; RIBAS, M. A.C. Trajetória do ensino de Filosof ia no Brasil. Disciplinarum

Scientia: Ciências Sociais e Humanas, Santa Maria, v. 2, p. 1- 13, 2001. Disponível em: http://sites.unifra.br/Portals/36/CHUMANAS/2001/trajetoria.pdf, acesso em 13/02/2017.

MENDONÇA, S. Pressupostos éticos da educação da solidão. Filosofia e Educação (Online), ISSN 1984-9605 - Revista Digital do Paideia. Volume 3, Número 1, Abril de 2011 - Setembro de 2011.

. Objeções à igualdade e à democracia: a diferença como base da educação aristocrática. ETD -Educação Temática Digital. v. 11, n. 1, p. 443-350, jan/jun 2012.

. Aristocratic education in Nietzsche: individual achievement. Maryland: Global South Press, 2018.

SAFA, Talita Carneiro Gader; MENDONÇA, Samuel. Educação moral: a busca da excelência a partir de virtudes aristotélicas e a formação do educador. Conjectura, v. 17, n. 3, p. 69-89, set./dez. 2012.

SÁ JÚNIOR, L. A. Reflexões sobre o ensino da filosofia no nível médio. HOLOS, Ano 26, Vol. 3. 2010.

TESSER, G. J.; HORN, G. B.; JUNKES, D. A Filosofia e seu ensino a partir de uma perspectiva da teoria crítica. Educar em Revista. Curitiba, n. 46, p. 113-126, out. /dez. 2012.

THIRY-CHERQUES, H. R. O racional e o razoável: Aristóteles e o trabalho hoje. Cad. EBAPE.BR, Rio de Janeiro, v. 1, n. 1, p. 01-11, Aug. 2003.

THORTON, M. T. Aristotelian practical reason. Mind, v.91, n.361, Jan. 1982. 